\title{
Perspective of the Economy Situation in the Fishing Industry of the Volta Basin in Ghana: Case Study of Dzemeni and Kpando-Torkor
}

\author{
Marian Adwowa Amu-Mensah"1, Frederick K. Amu-Mensah1, Nelson Obirih-Opareh² \\ ${ }^{1}$ Water Research Institute, Council for Scientific and Industrial Research (CSIR), Accra, Ghana \\ ${ }^{2}$ Scienceand Technology Policy Research Institute, Council for Scientific and Industrial Research (CSIR), Accra, \\ Ghana \\ Email: baarbs92@hotmail.com, fkamu.mensah@csir-water.com, nobirih opareh@yahoo.com
}

Received 31 December 2013; revised 3 February 2014; accepted 25 February 2014

Copyright (C) 2014 by authors and Scientific Research Publishing Inc.

This work is licensed under the Creative Commons Attribution International License (CC BY). http://creativecommons.org/licenses/by/4.0/

(c) (i) Open Access

\section{Abstract}

The paper examines the existing economic situation and how it operates following the introduction of cage culture. It assesses the challenges facing major fishing communities along the Volta Lake and describes government's role. Using a participatory rural appraisal, questionnaire administration and participant observation, data were gathered from two districts in the Volta Basin of Ghana. Key areas of the study included, limited accesses to information, ownership control of the means of production, financial institutions, decision making with regards to resource use, and management and investments in fishery. The result shows that soaring prices of fishery implements due to high exchange rates, coupled with declining fish stocks have reduced the profitability of the processing and sale of fish. About $60 \%$ of fishers interviewed agreed that the bulk of fishers have contributed to the decline in fish stock in the Volta Lake. Fishers also outlined three challenges namely the lack of access to information on best practices, high interest rates on loans $(10 \%$ $40 \%$ ) and lack of proper structural and institutional arrangements that account for the poorly regulated and managed fishery sector. It is expected that the introduction of cage culture innovation will promote sustainable production, distribution and improvement in fishery services and help to address the basic problems of fishing communities in the Volta Basin of Ghana. However, a review of local and national institutional arrangements for regulation and management of the fisher sector are crucial for long-term sustainability.

\section{Keywords}

Economic Institution; Inland Fishing; Volta Basin; Management; Innovation; Dzemeni; Kpando-Torkor 


\section{Introduction}

The economy of any community is based on the resources available to it and how well the people are able to extract and use them. The economic institutions, in this context are thought of as organizations, that engage in or provide services or products deemed economically central to a community's economy. This is in addition to the organizations in the society that are integral to the economic system or culture, such as the banking systems, investment markets or even a custom or tradition, such as providing family members with loans or children with weekly allowance www.wisegeek.com/what-factors-affect-economic-growth-rates.htm. Markets are based on institutions which according to Douglass North (1990) is the formal and informal rules that restrain human economic behaviour. They also include political institutions that develop laws, the cultural traits of society that direct people's tastes and behaviours, and other organizational structures such as fishing corporations, telecommunication, and financial institutions that provide financial services for its clients or members and non-profit organizations that make up the economy.

Siklos (2001) and Robert and Vincenzo (2012) explain that there are three major types of financial institutions deposit-taking institutions that accept and manage deposits and make loans available, including banks, building societies, credit unions, trust companies, individual money collectors and loan operators or companies. The others are contractual Institutions like the insurance companies and investment institutes like brokerage firms and Insurance, yet every society or community has its own financial institution that operates within the community.

The economic situation of many fishing communities in the Volta Basin has deteriorated Braimah et al., (2003) as a result of stagnating or even falling market prices, partly owing to an increase in the number of people who depend on fish as food and sources of income. Lenselink (2002), indicated that this dependency, may go far beyond those immediately engaged in fisheries to include a vast number of local and distant consumers. Kolding (2004) explains that a number of people who fish in the Volta have not kept pace with the quantity of fish being exploited. He further explains that, one does not expect to catch the same quantity and size of fish compared to when the number of fishers was less. In addition, there has been a steady increase in the efficiency of fishing boats, resulting in widespread overfishing in the Lake. Constant increase in premixed fuel prices in Ghana, importation of fishing inputs and the unstable purchasing power of the Ghanaian cedi against the dollar, has affected the fishing business. Consequently, assistants who are paid a share of the income generated by the catch have also suffered a loss of income. All these can mean that fisher are operating at a loss (Asante, 2004; Agyenim-Boateng, 1989).

Declining wild fish stocks, increasing consumption of fish and poor farm economy have produced a strong interest in fish production in cages as alternative avenues of business ventures. As with any production scheme, it is necessary to consider the advantages and disadvantages carefully before cage production becomes the chosen method of fish production (Masser, 1988). This decline has become a problem, with serious poverty, food security and health implications for those who depend on fish as food and a source of income. The government in an effort to boost and increase fish production has introduced cage culture, an innovative way of increasing fish production. It is expected that livelihood of the very poor fishers along the Volta Basin of Ghana would improve substantially with the innovation. Since the creation of the Akosombo Dam, the fish population in the Volta Lake has dwindled (Braimah et al., 2003, Sutherland et al., 2004). Riparian communities along the lake are faced with unsustainable fish harvest, lack of financial support and increasing demands on the lake's resources due to population growth etc., as contributing to fish decline in the communities. To meet this challenge, the Ghana government in collaboration with the Challenge Program on Water and Food under the Consultative Group on International Agricultural Research (CGIAR, 2004), intends to boost and increase fish production through the introduction of cage culture. Masser (1988) explains that cage culture is growing tilapia or any fish commercially in one of four-culture setting cages made of nylon nettings and bamboo frames, which floats on the water. This innovative way of increasing fish production in the fishing communities, aims at sustainable fishery productivity in the country as well as improving on the livelihood of riparian communities most of whom are poor. It also aims to check the over fishing of the native fish stocks.

Most of these communities lack basic economic infrastructure including easy access to big markets. Braimah et al., (2003) and Sutherland et al., (2004) indicated that the decline in the fishing industry of the lower Volta Lake during the creation of the dam compelled the different ethnic groups of people to move upstream into similar areas designated by the government. This has caused a decline in socio-economic activities as well as in cultural values. The problem that the paper tries to address is how the economic institution and related social in- 
stitutions like finance, health, governance, family and religion will be able to support, the new way of increasing fish production. Orville (2001) explains that social institutions are not buildings or places, but a social system of relationships, obligations, roles and functions. These are social concepts and practices, which also involve relating structures in a community. Literature indicates that the capability of the economic institution is greatly enhanced by health, governance and religion, which affects the individual's ability to choose or make sound decisions (Stuart, 1997; Sarfo-Mensah et al., 2003).

Theoretically, Rogers (1995) explains that once an innovation occurs it might spread from innovator to other individuals and groups. Parsons as cited in Haralambos et al. (1980) and Giddens (1990) also explain that performance of a society or economy as a whole provides certain necessities in the economy that facilitate the survival and development of any initiation, indicating that there is strength (capacity) in togetherness as well as in solidarity (Assimeng, 2006). The idea that the potential of an economic institution is mainly through support systems is evident in the form of funding or advice provided, Adger and Kelly (1999) and Amu-Mensah (2007). This is confirmed by Fukuyama (2006), who explains that less formal institutions can be made to work, if they are given the right leadership, judgment, information and political will. He also noted that even the best institutions will not work well in the absence of the supportive political culture.

In relation to this idea the activities of the social institutions were studied to assess their effectiveness and harmony between the workings of the economic institution. This is to help develop a broader view to support improvement in the livelihood developments of the people to ensuring optimum benefit from the study. The introduction of the fish cage culture is expected to have a rippling effect on all the surrounding communities, making it possible to ensure an increase in fish production, to improve the economic conditions of community members in the Volta Basin as well as reduce malnutrition whiles improving health. Fish cage culture utilizes an existing water resource and encloses the fish in a cage or basket that allows water to pass freely between the fish and the pond. It involves raising fish commercially in tanks or enclosures.

Today cage culture is receiving more attention by both researchers and commercial producers. The main objective of the paper examines the economic situation of inland fishing communities and nature of management in fisheries. It analyses the role of communities and government in the sector. In addition, positive and negative impacts of the economic institutions in increasing fish production through cage culture were also examined.

Therefore, this study was designed to examine the economic situation in inland fishing communities, analyse the role of community and government institutions in the management of fisheries and find out fishers' perception, of the economic situation.

\section{Methodology}

Dzemeni and Kpando-Torkor, the selected communities for the study are major landing sites for fish as well as major markets for various goods in the southern part of Ghana. These two markets serve a large part of the country with freshwater fish and processed fish. Dzemeni community under a traditional leader, has relative unity, hence they have respect for traditional rules and recognise chieftaincy issues. The study revealed that unlike Dzemeni, Kpando-Torkor with its different tribes, (Ningos, Fantis, Gas, and Nzemas) who also contribute to the number of settlers in the community are not very united. A chief fisher who is selected among the various groups, become responsible for the various ethnic fishing groups and hence the fisher-folks are not under any traditional chief, (South Dayi District Assembly Development Plan, 2006; Kpando District Report, 2005 and information from an in-depth interview conducted with Togbe Ken Adom of Kpando-Torkor and the Kpando District Assembly planner Mr Fred Alkty). The Kpando-Torkor community headed by tribal chiefs has created anonymity where there are no special rules, or traditions to follow to ensure sustainable management of the fishery resources.

Structured, semi-structured interviews and focus group discussions were the basic tools used in gathering economic institutional data, in addition to first hand observation. The study sampled two fishing communities within the Volta Basin. The approach was based on the size of the fish landing site, logistics, time factor and accessibility as well as market size for the sale of fish and fishery products in the Volta Basin. Fisher-folks selection was based on random sampling. The entry process of the programme was also examined amongst many other variables to see its impact on the programme. The breakdown of respondents is as presented in Table 1.

The analyses conducted, follow a detailed account of opinion leaders, government officials in the fishery sector and other stakeholders in the sector. Microsoft Excel and Statistical Package for Social Sciences (SPSS) 
software were used to analyse the quantitative data. And the qualitative data was analysed using Content Analysis.

The reluctance of the fisher to share information with the facilitators was a problem, especially in KpandoTorkor and this sometimes hindered the investigation. They were of the view that they have had enough of research and discussions and it was time for the government to put in place something tangible to help alleviate their poverty. Questionnaire for 10 of the respondents were partially completed.

\section{Results and Discussions}

\subsection{Socio-Economic Characteristics of Respondents}

The Communities of Dzemeni and Kpando-Torkor consist of 4100 and 3399 people respectively (2002 Census). Generally the study population of 182 in both villages give a higher proportion of males than females, suggesting further exploitation of the lake for fishing activities is a preferred activity for majority of men in the riparian communities. This is also supported by data in Table 2 giving an indication of the very energetic age group who can withstand the hardship of fishing activity on the lake as well as the taking up of cage culture as males.

\subsection{Respondents' Educational Background}

Levels of education for both communities showed that $68.6 \%$ completed primary education. Only $10.0 \%$ have completed commercial/vocational education, which seems to be the highest level of education attained. A significant number, $30 \%$ of respondents did not go to school and are regarded as not having any formal education.

However, most of these respondents have successful fishing businesses as fishers and fish possessors. One person was still in school, with 30\% having completed primary school. Results indicated that those with Middle School Leaving Certificate (MSLC) were $15.7 \%$ and those with secondary education were $12.9 \%$. Results also show that majority (61.4\%) of the fishers are between no schooling and just the basic education. These results might send danger signals to the adoption of new technology/innovation by the fishers thereby reducing the expected productivity of fish farming in the area. Indications are that the $38.6 \%$ of the rest of the respondent might be able to comprehend basic issues in fisheries innovation and could support the rest of the population. It would be desirable to extend some education in order to get the majority of fishers well informed about innovations introduced.

\subsection{Support and Influence of the Economic Institution in Fishery Activities}

Respondents were interviewed on their perception of the different social institutions in the two communities. The two most influential social institutions, religion and family seem to be very supportive in the lives and activities of the fishers and therefore such institutional support will be useful to the innovation. According to the

Table 1. Breakdown of respondents.

\begin{tabular}{ccccc}
\hline & \multicolumn{2}{c}{ Qualitative } & \multicolumn{2}{c}{ Quantitative } \\
\cline { 2 - 5 } Community & $\begin{array}{c}\text { Key Informants } \\
\text { (In-Depth Analyses) }\end{array}$ & $\begin{array}{c}\text { Focus Group/Rural Participatory } \\
\text { Appraisal }\end{array}$ & Interviews & Total \\
\hline Dzemeni & 10 & 41 & 40 & 91 \\
Kpando-Torkor & 10 & 41 & 40 & 91 \\
Total & $\mathbf{2 0}$ & $\mathbf{8 2}$ & $\mathbf{8 0}$ & $\mathbf{1 8 2}$ \\
\hline
\end{tabular}

Table 2. Respondents age and sex distribution.

\begin{tabular}{|c|c|c|c|c|c|c|c|}
\hline \multirow[b]{2}{*}{ Sex } & \multicolumn{6}{|c|}{ Age Groups } & \multirow[t]{2}{*}{ Total } \\
\hline & $15-24$ & $25-34$ & $35-44$ & $45-55$ & $56-64$ & $65+$ & \\
\hline Male & 3 & 5 & 25 & 8 & 0 & 0 & 41 \\
\hline Female & 0 & 2 & 13 & 6 & 8 & 0 & 29 \\
\hline Total & 3 & 7 & 38 & 14 & 8 & 0 & 70 \\
\hline
\end{tabular}


respondents who ranked theses institutions high, the leaders of the family (Mother, Father) and religion (Church leaders), easily influence their decisions because of the financial support and advice from these institutions. The analysis gives an indication of how the fishers' attitudes could be shaped into making positive decisions on livelihood by using the influences of these two institutions. It is worth noting that, the economic institution is represented by the fishery institutions (Chief Fisher, fishery officers and market establishment) and this was ranked as third most influential and supportive to fishery activities.

Ranking of institutions based on support and influence on fishery activities is presented in Figures 1 and 2. Dzemeni and Kpando-Torkor's ranking of the institutions were similar although, the scores were different, with the economic institution placing third.

The reasons given by respondents, for choosing, or using the particular social institution with respect to fishing activities, include the availability of the institutions to support their needs, the quality of their services, the kind of authority they exercise and the good relationships they have with fishers. From Figure 1, respondents indicated that the economy which was represented by the fishery institutions, help to bring in jobs while assisting them to exchange goods and services through which they are able to earn a living to feed their families although it is difficult to acquire loans from the banks. Some respondents said the economy creates the avenue for the easy disposal of their fishes and wares to people from other towns and cities for income. They also indicated that the price of fish keeps increasing depending on the level of catch and cost of fuel for their boats. This makes it difficult for many clients to patronise the fish, from their markets. They make losses during such times, especially when they are unable to profitably dispose of their catch. Respondents believe that the nature of infrastructure and access to financial institutions do not encourage improvement of the livelihood of the fishers or increase the patronage of customers to their communities. Despite the state of affairs indicated by respondents, $72.9 \%$ of them expressed their readiness for an innovation like fish cage culture, the rest agreed to have an innovation with the hope that government would bring in some form of support.

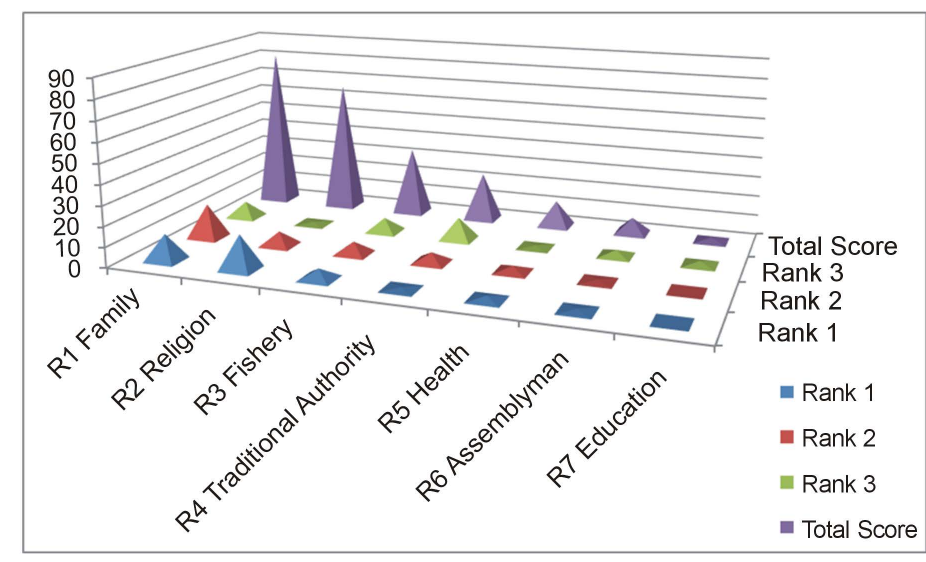

Figure 1. Institutional ranking in Dzemeni (R1 = Rank 1).

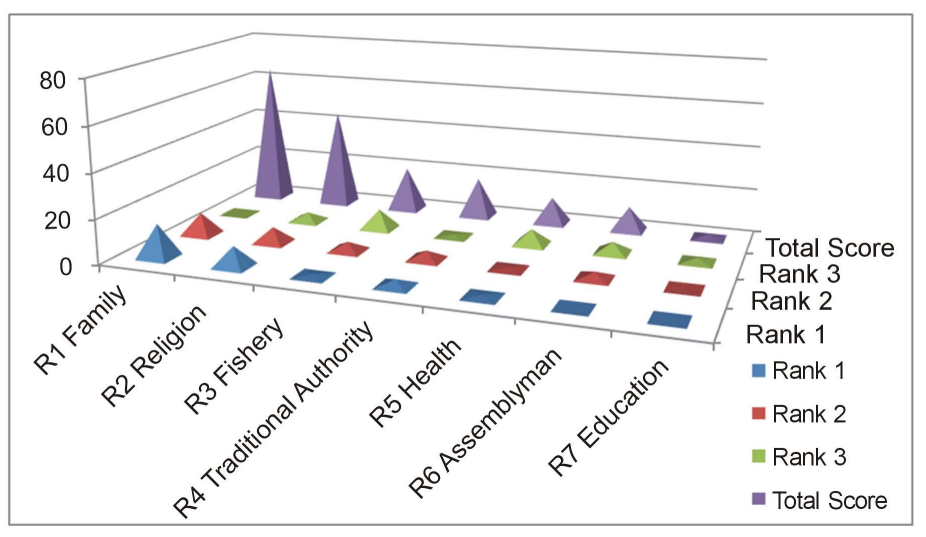

Figure 2. Institutional ranking in Kpando-Torkor (R1 = Rank 1). 


\subsection{Role of Community Institutions and Government Institutions in the Management of Fisheries}

The family controls the economic production, with the head of the family, (the man) as the owner of the business. In some cases, women are the owners of the fishing business in the family. This indicates that no strict rules or taboos hold back any women in the riparian communities studied, in their participation in fisheries, or from becoming the owner of a fishery business. Rather, the biological nature of women (menstruation) is a taboo that prevents women during this period in their life's cycle, from entering the Volta Lake. Respondents indicated that family members support their fishing business by advancing money to their spouses, children, brothers and sisters, who need money to start a business or to expand their fisheries business. Other fishers give their children out as helpers (processing and sale of fish) or assistants in the fisheries business of other family members. Such assistants become the sources of labour for most fishers in addition to their own children.

Data confirmed that there is little or no conflict amongst the fisher due to the interventions from the family, church and traditional authority. Data on conflicts between the different tribes in the community shows that, $29 \%$ of the respondents explained that conflicts exist. Whilst $44 \%$ of fishers gave an indication that there were no conflicts between the ethnic groupings, $27 \%$ of respondents refused to answer. The $29 \%$ respondents who answered in the affirmative explained that there were conflicts over the different methods of fishing("NifaNifa" and "atidzja", the two-inch sized nets and most of the unauthorised methods of fishing), yet they try to accommodate each other and work out their differences through their chiefs and the churches. Fishers also gave an indication of how responsible they feel towards fisheries resources and their management. The $23 \%$ of the fisher-folks from the locality, felt more responsible, because they are concerned about what happens in their community and recognise that their livelihood depends on the available fisheries resources. The migrant fishers, who are $77 \%$ of respondents, are still closely linked to their home towns giving an indication that, they do not contribute much to the development of the community in which they derive their livelihood. This is confirmed by the migrant fishers' frequent visits to their hometowns during festivals and funerals to contribute to the development of their towns. Yet the migrant fishers are also solely dependent on the sustainability of the fisheries resources. It is therefore possible that they are more careful and uniform in their attitude towards fisheries resource use, as they indicated.

All the religious institutions exist harmoniously with each other, according to the chief of Dzemeni, the religious institutions come together to participate in communal labour, provide streetlights through donations from church members and participate in other developmental activities in the area that enhances the development of their fisheries activities.

Most of the churches offer financial support for the needy, the sick and the old in both communities. Some fisher-folks in the fisheries business indicated that, the church supports them financially and gives them advice on the management of their businesses during church meetings.

\subsection{Role of Government in Inland Fishery}

Government was represented by the assemblyman and fisheries officers. The role of the fisheries officer who is a government official, is to collect data from Mondays to Fridays on fresh and smoked fish, transported out of town. Fisheries officers at post in the study areas explained that their job is to collect data on quantity and average weights of fresh fish landed in the communities and processed fish which, the fish traders transport to other places in the country. This information is gathered weekly and monthly for the fishery report. The report or data collected is sent to the Accra Department of Fisheries, of the Ministry of Food and Agriculture (MoFA) (MoFA, 2004) for further analysis and to aid policy formulation on fishery activities. A monthly report is then sent to Kpando, the head office and then to Accra the capital of Ghana for onward transmission to Rome. The Ghana government according to the officers, does not impose taxes on the fisher-folks' activities. However, some levies are collected from those who transport smoked or processed fish to others towns. Officers of the fisheries department also prepare waybills for large quantities of fish that leaves the communities. Information on inland fishing according to the fisheries officers is used to estimate inputs including fishing gear that is brought into the country.

According to both officers, they also report other activities on the lake, especially storms, death on the lake as well as missing gears. Information concerning laws and regulations from government is relayed to the fishers through workshops by the local fisheries officers. Through the same channel, fishers' concerns are sent to gov- 
ernment through the local office. The fisheries department works in collaboration with the district assembly, which is also concerned with the development of the people in the communities.

The "Assemblyman" in each area, coordinates the affairs of the government in the community, through the district office within the area. In emergencies where people's lives and property are threatened, the fisheries officers intervene to help save the situation. The fisheries offices also report illegal uses of fishing methods or gears, to their headquarters for further action. This helps the country to make the necessary planning towards the areas with difficulties. Fishing nets, outboard motors and other fishing gear are dispatched to the fishers through the fisheries offices in the communities. In this way, the local government is able to ensure easy identification and registers all the fisher groups in the riparian communities of the Volta Basin. Despite government's effort to intervene in the supply of the means of production, individual businesspeople also bring in similar implements since the supply from government is not regular.

The Volta River Authority (V.R.A.), according to the chief, holds the Volta River in trust for the Government of Ghana. This function is currently delegated to the Water Resources Commission, which has the mandate to take care of Ghana's water resources in collaboration with other agencies and organisations. V.R.A. was responsible for resettlement of the riparian communities who were displaced by the lake formed because of the dam at Akosombo.

Most fishers send information to other fishers during their long travels from community to community to catch fish. It takes about two to five days to move between communities to meet and communicate with each other. The occasional meetings of the fisher's associations and other groups within the communities, enable fishers to receive information. This implies that the communities receive information at different times, depending on when a fisher gets to the next community. Six respondents indicated that they get information from friends, while others indicated that information on fisheries activities is handed down to them through the chief fisherman or in the case of Dzemeni, the chief of the town who plays a major role in making sure they receive every information. Others indicated that the fisheries officers in the communities organises forums to educate them when the need arises, sometimes once in a year or not at all.

It is evident from information gathered from the government officials that, the government institutions do not deal directly with all the fishers. Development plans and the development of the riparian communities are executed through their officers at the national or district level. The plans are then handed down at different levels of the government institutions and departments until it gets to the fishers. It is therefore very difficult for someone at the national or district level to get first-hand information on what really goes on in every community. This makes communication between government and fishers ineffective for proper management especially in the event of an innovation in fishery.

\subsection{Type of Market}

Of the 41 male fishers interviewed $78.0 \%$ indicated that the women get richer through the system of credit and there is a prolonged and increased indebtedness of male fishers to their wives and other female money lenders. Some fishers also explained that they do not have an appropriate way of pricing their fish and in many cases the "Market Mummies" rate the prices of the fish very low especially when market days in the communities coincides with that of other towns. The fishers are forced to sell their fish at very low prices due to lack of customers. Fishers do not get the fish's worth and therefore they are unable to put together a working capital or pay for their loan. The most important issue in the fishery production to the "market mummies" and money lenders is capital recovery.

Some of the fisher-folks make use of outboard motors on lease to fish at GHC40.00 per day. Leasing of outboard motors has become a source of income for some money lenders and "market mummies" making them control the means of production. The means of production are owned primarily by private businessmen and women. Undoubtedly decisions regarding fish production and investment are determined by private owners in both communities.

It was identified that most women owning fishing gear, support other fishers financially and make demands on the total catch of the fisher as payment for the financial support rendered them. This gives an indication of a form of barter trade where means of production are exchanged for fish. It was observed that $65 \%$ of respondent exchanged fish for other goods and services in both communities. A recent (11th December 2013) documentary aired on TV3 (TV3 Media Documentary, 2013) an Accra based media house confirmed this form of trading in other riparian villages. A snapshot of the documentary is shown in Figure 3. 


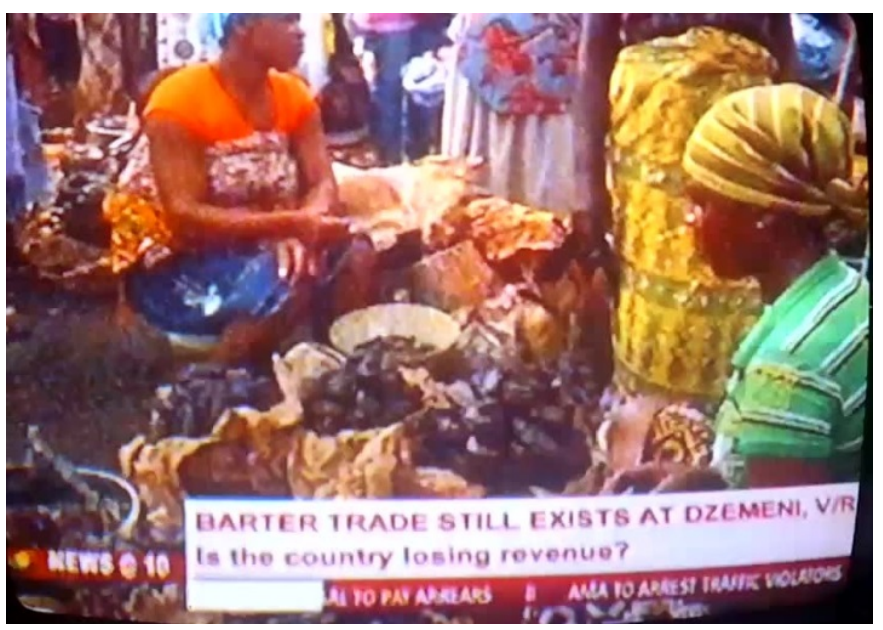

Figure 3. Barter trading captured on televison.

Few women in the community like Eva Atichobie, fishes, smokes fish and also sell fresh fish. She is also a "middleperson" buying off the catch from other fishermen. Women make up the dominant group when it comes to adding value to the fish, through smoking, salting, freezing, drying and marketing of fish. An analysis of the income of some women in the fisheries business was within a range of between one thousand cedis to two thousand cedis a month. During the bumper harvest some women can earn around four thousand to ten thousand cedis a month.

The suppliers of fuel for outboard motors indicated that, the supply of premix fuel to the fishers is on credit and this tends to freeze their capital for business. It is clear that this situation does not encourage efficient operation of the markets. This could hamper the fish production for the improvement of livelihood and can mean operating at a loss. The major suppliers of premix fuel for the engines of the outboard motors are the Oil Marketing Companies (OMCs) such as, GOIL Star, and Allied Aviation. Some also indicated that the prices of goods and fishing inputs are very high due to the price hikes in fuel. According to $94.2 \%$ of the respondents, it is difficult to earn a living or sustain their families since loans are not easy to come by and if secured, the interest rates are very high. Interest rate on loans ranges from $10 \%$ every week from moneylenders to $40 \%$ per annum by the banks.

\subsection{Infrastructure and Financial Institutions}

The market area consists of both open fish stalls along the Volta Lake in Dzemeni and Kpando-Torkor and covered stalls. Many of the traders prefer to sell in the open market, due to its closeness to the lake and easy access to boat and ferry passengers who are their main source of market. The Kpando-Torkor market is part of a fisheries complex with fairly well developed infrastructure. It includes a fisheries school, store and a boat-building yard. Information from the Ghana Districts homepage on the internet (http://www.ghanadistricts.com) indicates that the facilities are currently not in use and have deteriorated. Dzemeni's open-air fish market is patronised by people from all over Ghana and Togo. Although the infrastructure in Kpando-Torkor market is much better, Dzemeni has a larger market than Torkor. Respondents indicated the need to improve on the market facilities, since the whole market becomes muddy and unhygienic during the rain. The fishers said the state of the market does not encourage outsiders to enter their markets to trade. Shown in Figures 4 and 5 respectively, are typical markets scenesfrom the two areas.

Fisher-folks in Dzemeni explained that the formal banking system is not very convenient for them due to high lending rates and the complexity of associated paper work. Among the banks that the communities can access in and around their localities are the Agricultural Development Bank, Ghana Commercial Bank, Anum Rural Bank and other rural banks.

Traditional saving and credit groups known as "Susu" also exist in the communities. Though most of the fishers in Dzemeni have not made use of this system, some fishers are members of such "Susu" associations. In Kpando-Torkor, most of the "Susu" groups have died down due to mistrust among the fishers, but it is their main source of funding. 


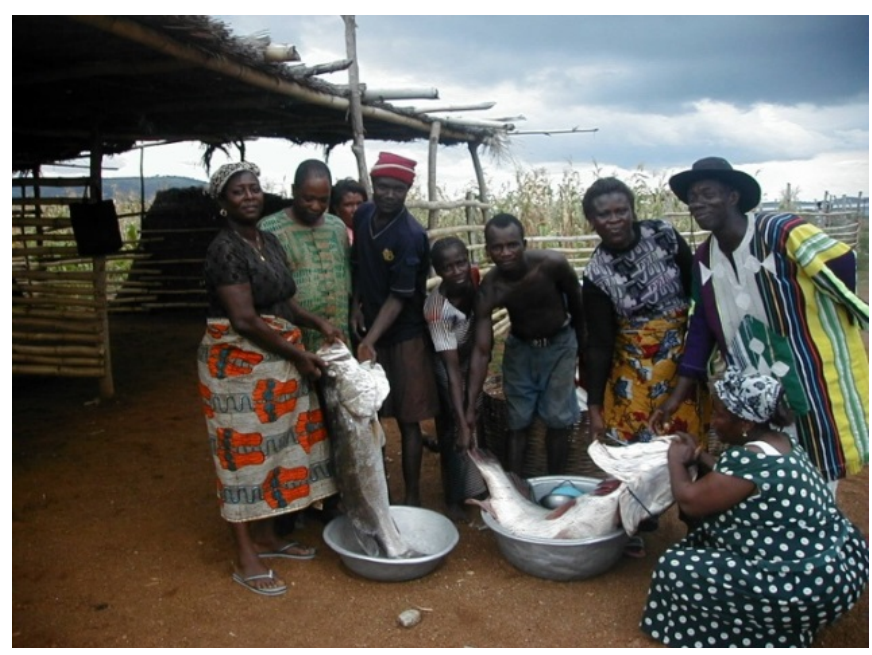

Figure 4. Typical market in Dzemeni showing fresh fish catch.

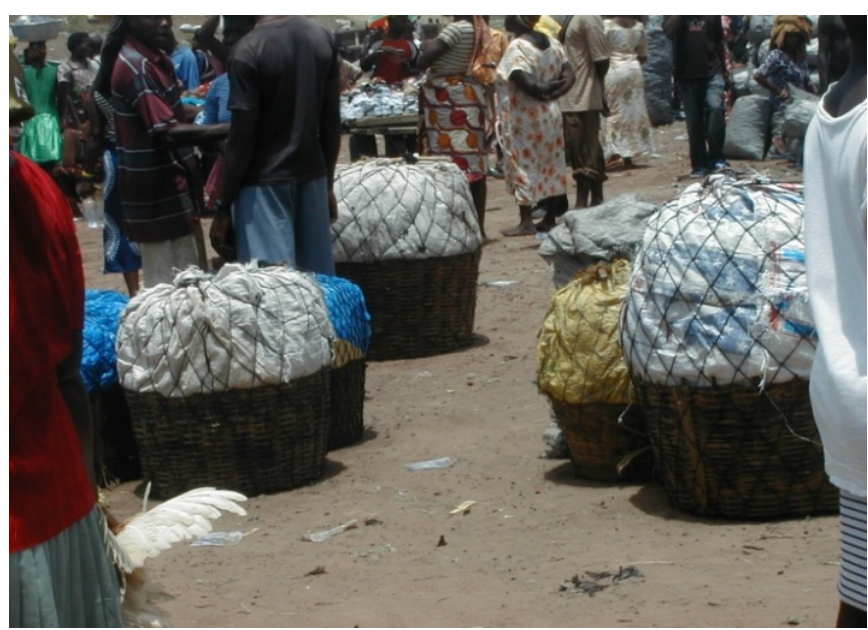

Figure 5. Typical market in Kpando-Torkor with baskets of smoked fish ready to be transported.

Sometimes Ten (10) to Forty (40) members make up the "Susu" group, who make periodic contributions to a collector, who is not necessarily a fisher. On daily, weekly or on monthly basis, members contribute to the fund. The collector arranges for each contributor to receive the total contributions for the month in bulk. Each member in turn collects the share of money until the money collection cycle ends with the last person on the "Susu" list, after which the rotation begins again.

There are no banks in Kpando-Torkor, but the service could be accessed at the main town of Kpando which is about 5kms away. These banks are the Ghana Commercial Bank, "Weto" Rural Bank, Asubonteng Rural Bank as well as other financial services like the "Susu" saving and credit service. Most fishers indicated that they save money for future needs by investing in cows, building of houses for rent and in the case of some women they buy jewellery and cloth. According to respondents they sell most of these items in times of financial crises, to make ends meet. Others also save with the banks, to enable them access loans available in the banks, although according to respondent this is difficult to access.

\subsection{Expenditure}

\subsubsection{Labour}

Most of the fishers are private owners who employ others to work for them. The representation of employees in the data is low because most of the employees are not registered members of the various fisheries associations. 
Even though the researcher attempted to get as many people working in the fishery sector, this proved unsuccessful. Majority of the respondents were from the groupings of the local associations within the two communities, leaving out those who were not in any group.

From Figure 6, 14\% of the respondents said they use their family members as assistants in their fisheries activities, $14 \%$ said they make use of their children after school. Those who employed other people to work for them were $62 \%$ forming the majority and $10 \%$ of the respondents explained that they work alone since they are not financially sound to pay wages.

They indicated that most of their children were either very young to help or are in schools outside the district. If this last explanation is to be accepted then majority (62\%) of the respondents are in the financial position to employ people to work for them. Most of the respondents explained that they employ people from "over bank" meaning the Afram Plains, Yeji and other towns in other regions. Most of the fishery assistants have employment on contract bases and work for a period of one to four years or more, which helps the employee who is in most instances an apprentice, to learn the fisheries trade.

Payments are either in cash or in kind. Most of the permanent employees interviewed indicated that they were part of the extended family. Other employees also came from the locality. The fishers indicated that with the exception of the permanent employees, they pay the rest according to the seasonality of the fish. Payment is between GHC100.00 - GHC250.00 per month. Casual workers are employed only when fish is in season and full-time employees are usually paid by the day in kind, cash or both. The employee receives an amount of GHC30.00 to GHC80.00, depending on the kind of job and strength needed for the job, and two fish. Some respondents numbering $46.3 \%$ indicated their preference for cash payments, $7.1 \%$ by produce and $17 \%$ indicated that they are paid in both cash and kind, indicating a form of barter. Those who work with their children, that is $12.1 \%$ of respondents explained that they support the children in school and provide for their needs better, since the support from their children helps to increase their revenue from the fisheries activities. Others representing $6.2 \%$ indicated that they share the revenue from the produce, based on a ratio of 1:4. The employee takes one part but though the employer takes four parts the two parts are reinvested. Fishers who worked alone were $11.3 \%$. There is an indication that the main economic activity in the area that brings the most revenue to the people is the fisheries activities since it employs people from within the community as well as communities in the periphery towns and beyond.

\subsubsection{Means of Production}

Most fish processors' expenditure is on salt, firewood, ice blocks, rent for storage area and transportation by canoe, carts and vehicles. The fish processors indicated that they spend about GHC250.00 to GHC1,500.00 a month depending on the quantity of fish to be processed. In the trading of fish, transportation, storage, market space (market toll), and labour are the areas that a lot of money is spent. Most of the traders interviewed

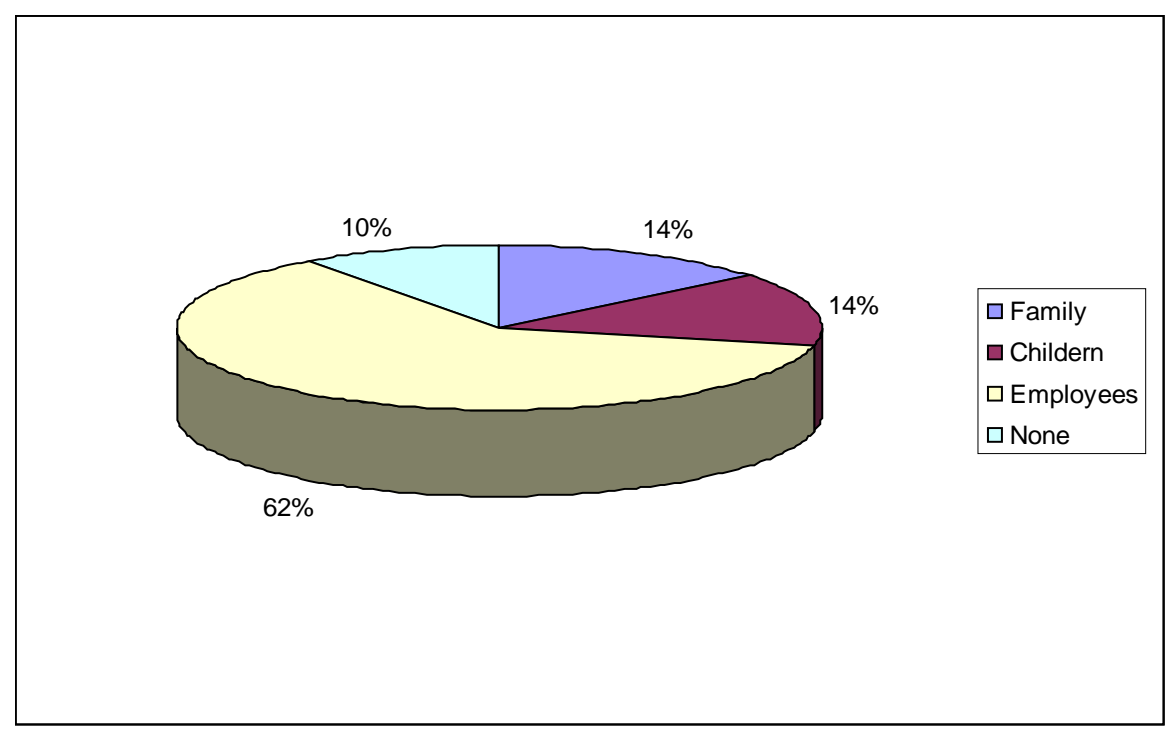

Figure 6. Category of assistants. 
indicated that they spend between GHC200.00 and GHC600.00 a month on transportation. Most respondents explained they spend GHC300.00 to GH৫1,000.00 a month on fuel for their out-board motors, depending on the fishing season and number of boats on the Lake.

The fishers complained about the high cost of fishery inputs and other expenses, which relates to fisheries activities. According to the fishermen the price of an out-board motor is about GHC24,800 and to be able to do good business you would need two or three out-board motors. Data collected revealed that a 72-foot passenger boat "Agbawui", made from the "Odum" tree, costs between GHC7,000 and GHC15,000. A 32-foot canoe "Service" which earned its name from its speed because it uses out-board motors, costs between GHC13,000 to GHC15,000. The cost of an 18-foot canoe propelled by paddle is between GHC7,000 and GHC 8.000. The other canoes are powered by a combination of out-board motors and a paddle which is used to move the canoes closer to the shores. Fishermen who cannot afford the out-board motors lease them at GHC 40.00 per day.

Traps made of 1 inch nets and palm fronds are purchased for between GHC15.00 and GHC25.00 each depending on the size. According to the respondents one needs about twenty to forty traps within a month to be able to catch enough for sale and consumption. This brings the total cost of traps to an amount of GHC1000.00 using the maximum figures of GHC25.00 and forty traps. Most of the traps require bait which costs GHC330.00 to GHC2800.00 depending on the kind of trap, meanwhile the bait for the trap lasts for only three weeks to a month. The fishers using the "Atidzja" trap, spend between one thousand to one thousand four hundred cedis depending on the season for fish. Most of their expenses go into purchasing tree branches, from landowners to construct the "Atidzja" and trucks to cart the branches and small trees to the lakeshore. In addition they spend money on bags of maize and dried fish which is used to prepare the bait. On the average, most fishermen spend from GHC800.00 to GHC10000.00 a month on these expenses that includes payment of employees. Looking at the expenditure of fishers, there is the likelihood that they can afford to purchase cages for the cage culture or form cooperatives to purchase a cage or two. Some fishers interviewed own 2 to 70 bundles of different sizes of nets, ranging from size 2 to 7 . A bundle of fishing net, (182.88 m or $200 \mathrm{yd}$ ) costs about GHC640.00, depending on the type and size of fish caught. Nevertheless data indicates that, $60 \%$ of the 182 fishers interviewed agreed that the lack of fish supply is population driven, $28.8 \%$ said it was due to improper monitoring and control, whiles $11.2 \%$ indicated that it was a natural process from climate change. Respondents' age group structure ranged between 15 years and 64 years, majority being the age of 35 to 44 years.

\section{Discussion}

The existing economic institutional system is more of a combination of capitalist and barter trading. The owners of the means of production mostly the "Market Mummies" operate with the aim of making profit although in certain instances, fish is used in exchange for services rendered as well as purchases made, indicating a barter system of trade. In this way, the very poor are able to trade away items they do not need, for items they need, ensuring some equity in the distribution of resources.

There is minimal government regulation with maximum family or traditional regulation ensuring freedom for everybody to operate in the market. This creates an enabling environment for operators to take advantage of fishery innovations. Lack of infrastructure for the fishery business from government indicates minimal regulation of the market system by government (Schumpeter, 1943). Hence the minimal government input does not create the proper market environment to aid fishery innovation to progress in comfort, convenience and efficiency.

Results indicated the appropriateness of using both traditional and government institutions in managing the fishery sector, since majority of the fishers do not come from the area and may not adhere to the traditions of the communities. Indication are that fishers' attitudes could be shaped into making positive decisions on livelihood by using the influences of religion and family institutions for innovations in fishery as well as equitable distribution of resources (Stuart, 1997).

It was obvious from the study that information from government is handed down at different levels of the government institutions and departments until it gets to the fishers. Most respondents indicated that they receive their information from other fisher when they meet on the Lake. In certain instances fishers who travel from community to community in search of fish usually bring in information. Sometimes fishers would have to wait for several days to receive information from the other fishers and it does not assist fishers or policy makers to make informed decisions about fishery management. In some cases, information gets to the end users very late or not at all. Limited accesses to information, in both communities does not encourage coordination of economic 
activity (planning) and investments in fishery (Benabou 1996). Information is meant to be a guide to potential investors in aquaculture activity to ensure sustainable innovation. The use of mobile phones to send information across the communities could be encouraged at the local level with the chief fishers. In addition, access to communication lines should be improved in all the fishing communities.

Fishers go through a lot of difficulty considering the decline in fish stock which was confirmed by $60 \%$ of the 182 fishers interviewed, coupled with high interest rates, ranging from $10 \%$ every week from money lenders to $45 \%$ annually from the banks. In addition, fuel price hikes in the country have reduced the profitability of the fish trade in the study communities. From the study these interest rate are not favourable for long-term innovation projects (Amable et al., 1995). The "Susu" system and family support in these communities is rather seen as the major source of finance for the fishery sector although the system is not well developed. Therefore this institution needs to be regularised to ensure that no individual absconds with the fishers' money to ensure efficiency of the economic system.

Labour is a very important factor in any fishery innovation, (Norman, 1972). Two kinds of labour were identified in the study areas; family labour and hired labour. Family labour is very important in fish production in the area because majority of the fishers fish in the lake which is close to their home. Nevertheless the analysis shows that hired labour is a major component of the resources used in carrying out various operations in fish production in the study area. It is expected that fishery innovation will enhance the use of hired labour within the study area, to create more jobs for the youth. Majority of the respondents have little or no formal education at all. For a successful introduction of an innovation like fish cage culture, fishers with some specialized training in aquaculture fishery would be required. The study also reveals that labour cost ranges between GHC100.00 GHC350.00 per-month for uneducated labour and this could translate to imminent doom to fishery innovation sustainability, taking into consideration the number of trained labour who would be needed to handle the fish cage culture. On the other hand, one could say that the nature of the cage culture brings in more fish in the shortest time than the natural fishing system and therefore the sale of fish from the cage culture could sustain the labour cost.

\section{Conclusion}

Preliminary fish cage culturing initiative is perceived by respondents in the study communities as a positive undertaking and a good idea to satisfy increasing demand for freshwater fish in Ghana especially following several fishery workshop promotions by Water Research Institute of the Council for Scientific and Industrial Research, (CSIR-WRI) in the communities. However further survey and assessments would still have to be done on income and expenditure in fishery. This is for the sake of economic and financial analysis of fish cage culture and the estimation of economic value, for incorporation into cost benefit analysis.

Both communities operated a mixed economic system (capital and barter). Majority of respondents use credit facilities to finance their fishing operations from the traditional "susu" system and from the banks, although credit facilities comes with high interests rates of $10 \%$ to $40 \%$. The availability of credit facility to fishers is expected to boost fish productivity if it is utilized judiciously.

Proper access to the right quality and timely information, high cost of means of production, lack of financial resources, fluctuation in the prices of fish, were the most serious problems militating against the fishing enterprise in the study areas. This was followed by inadequate market infrastructure and quality of available skilled labour among others. Mobile phones could be used to disseminate fishery information to the remotest areas in the communities to ensure that policy is communicated effectively and to ensure that fishers are abreast with current information.

This study therefore concludes that, despite problems and challenges militating against fishers in the economic system, innovation to increase fish production could be viable and attractive to those who so wish to invest in the area. This is with particular reference to the big-time operators who make investment of over GHC8000.00 to GHC20000.00 a month in the fishery business.

\section{Recommendations}

The research policy thrust is for the government to encourage and support social institutions so that new techniques would be adopted in the study area. There is also a need for government to subsidize some of the means of production to reduce the difficulties faced by fishers. 
It is also recommended that innovation in fishery by government and stakeholders should be done in conjunction with the structures existing in the social institutions to ensure maximum benefit to the communities. Strengthening these institutions could assist in promoting these innovations.

The factors affecting fish production and therefore an innovation in fishery as shown in the study, indicates that, the most important problems encountered in fish production were access to capital and information. The paper therefore recommends that the "Susu" system which is seen as the major source of finance in these communities should be regularised by government to prevent individual operators absconding, with the little earnings of the poor fishers.

In addition, provision of loan facilities from the banks should be improved for fishers in cooperatives.

\section{References}

Adger, W. N., \& Kelly, P. M. (1999). Social Vulnerability to Climate Change and the Architecture of Entitlements. Mitigation and Adaptation Strategies \#4 pp 253-266. The Netherlands: Springer Publishers.

Agyenim-Boateng, C. E. (1989). Socio-Economic Conditions in the Fishing Communities in the Yeji Area. Report for Integrated Development of Artisanal Fisheries in Yeji. Ghana: FAO.

Amu-Mensah, M. A. (2007). The Capacities of Social Institutions to Cope with Fishery Innovation, (A Case Study of Dzemeni and Kpando-Torkor, Fishing Communities in the Volta Basin). An MPhil Sociology thesis, Legon: University of Ghana.

Asante, F. A. (2004). Socio-Economics of Fisheries Dependent Communities in the Volta Basin of Ghana. Power Point Presentation Workshop on Challenge Program on Water and Food, Legon: University of Ghana.

Assimeng, M. (2006). Understanding Society; An introduction to Sociology for African Students. Accra: Woeli Pub.

Butler Stuart, M. (1997). Why Strong Social Institutions Are Needed to Survive Economic Growth (pp. 1, 3, 6). Washington DC: The Heritage Foundation.

CGIAR Challenge Program on Water and Food (2004). World Water Crisis—The Volta River Basin—Global Research Effort to Produce More Food with Less Water. http://www.waterforfood.org

Douglass North (1990). Institutional Change and Economic Performance. Cambridge: Cambridge University Press.

Fukuyama, F. (2006). Development and the Limits of Institutional Design. Paper Presented at the Seventh Annual Global Development Network Conference, St. Petersburg. http://www.ghanadistricts.com

Giddens, A. (1990). An Introduction to Sociology (2nd ed., p. 480). London School of Economics, New York City: W. W. Norton \& Co Inc.

Kolding, J., \& van Zwieten, P. (2004). Improving Productivity in Tropical Lakes and Reservoirs, Project. Manuscript Commissioned by the Challenge Programme on Water and Food.

http://www.aquaticecosystems-cpwf.org/pdf/100.\%20Manuscript_Kolding.doc

Kpando District Assembly (2000-2005). Annual Report. Kpando: Kpando District Assembly.

Lenselink, M. N. (2002). Rural Development: Participation in Artisanal Improved Livelihood in Fisheries Management for West Africa. Fisheries Technical Paper FAO Corporate Document Repository \#432. Rome.

Masser, M. P. (1988). Cage Culture. SRAC Publication. http://www.growfish.com.au/Grow/Pages/Site/Glossary.htm

MoFA (2004). Annual Report: Information on Fisheries in Ghana. Accra: The Directorate of Fisheries, Ministry of Food and Agriculture.

Orville, B. J. (2001). Social Institutions: What Is Culture?

http://orvillejenkins.com/whatisculture/socinstitutcul.html

Parsons as Cited in Haralambos M. and Holborn (1980). Sociology, Themes and Perspectives (p. 30). London: University Tutorial Press.

Robert, W. E., \& Vincenzo, Q. (2013). Money and Banking: Chapter 2 Section 5: Financial Intermediaries. http://www.saylor.org/site/wp-content/uploads/2012/06/ECON302-1.2-1st.pdf

Rogers, E. M. (1995). Diffusion of Innovations (4th ed.) New York: Free Press.

Sarfo-Mensah, P., Braimah, L. I., \& Kunu, A. J. (2003). Institutions Influence on Policies-Sustainable Fisheries Livelihoods Programme (SFLP). Stakeholders for Inland Fisheries Co-Management Project Report. Accra: DFID.

Schumpeter, J. A. (1943). Capitalism, Socialism, and Democracy (6th ed., pp. 81-84). London and New York: George Allen \& Unwin.

Siklos, P. (2001). Money, Banking, and Financial Institutions. Canada in the Global Environment (p. 40). Toronto: McGraw-Hill 
M. A. Amu-Mensah et al.

\section{Ryerson.}

South Dayi District Assembly (2006). Annual Report. Kpeve: South Dayi District Assembly.

Sutherland, J. W., Agadzi, K. O., \& Amekor, E. M. K. (2004). The Volta Basin, Water Resources Management for Fishery Development Workshop Report on "Integrated Water Resources Management in Ghana” (p. 4).

TV3 Media Documentary (2013). Barter Trade Still Exists at Dzemeni. Accra: TV3 Network Limited. 